\title{
ESCRITAS DA BRASILIDADE: SUBJETIVAÇÃO E POLÍTICA LUSÓFONA NA DOCUMENTAÇÃO VERNACULAR
}

\section{(Writings of Brazility: subjectivation and lusophone policy in the documentation of the vernacular)}

\author{
Anderson Salvaterra MagalHães (UFSM)
}

\begin{abstract}
Resumo: Neste trabalho, o objetivo é demonstrar como escritas sobre o Brasil fundamentam e são fundamentadas por valores determinantes dos discursos que constroem o senso de vernáculo. São analisados a "Carta" de Pero Vaz de Caminha, escrita chave para a produção do discurso da brasilidade, e o poema "Erro de português", de Oswald de Andrade, tomado como reformulaşão da escrita fundadora. A implicaşão ética do acabamento estético das duas escritas em lingua portuguesa articula processos de subjetivação que definem identidades culturais possíveis e atualiza uma política linguística que confere tensão entre o caráter genitivo e locativo do vernáculo, respectivamente, do Brasil e no Brasil.
\end{abstract}

Palavras-chave: Escrita. Vernáculo. Subjetivação. Política lusófona.

Abstract: The aim in this paper is to demonstrate how writing about Brazil simultaneously founds and is founded by values determinant of discourses which build the sense of a vernacular. Two documents are analyzed: Pero Vaz de Caminha's "Letter", a key piece of writing for the production of the discourse of Brazility, and Oswald de Andrade's poem "Erro de portugues", a reformulation of the founding piece of writing. The ethical implication of the aesthetic accomplishment of the two pieces of writing in Portuguese articulates subjectivation processes which define possible cultural identities and actualizes a language policy which conveys tension between the genitive and locative character of the vernacular, respectively, of Brazil and in Brazil.

Key-words: Writing. Vernacular. Subjectivation. Lusophone policy.

\section{INTRODUÇãO}

A questão vernacular brasileira atualizada em escritas históricas e literárias envolve três tópicos interdependentes: política lusófona no Brasil e estabelecimento da língua do Brasil, organização dos processos de subjetivação e construção de identidades coletivas, escrita e documentação da 
memória cultural brasileira. Cada um deles recupera uma dimensão do processo deflagrado pelo empreendimento lusitano que projetou unidade política para a multiplicidade étnica, cultural, linguística etc. do espaço que hoje se identifica como Brasil. A dinâmica social hodierna que promove e é promovida por uma coletividade autodefinida Brasil viabiliza o reconhecimento de um vernáculo, e o programa colonizador português deve ser destacado como condição fundadora desse panorama. Assim, abordar a construção do senso de pertença e de particularidade brasileira implica tratar da tensão entre as identidades que estabilizam o múltiplo, plural, diverso num grupo socialmente articulado e as alteridades que impedem a fixidez homogeneizante do grupo.

A noção de vernáculo advogada compreende toda e qualquer manifestação dos laços sociais que costuram coletividades e atualizam o funcionamento cultural. Arte, costumes, organização política; diversos são os planos de expressão dos valores que fazem do múltiplo o coletivo, e a língua é, sem dúvida, peça chave nesse processo. Isso porque a língua torna possível significar todas as manifestações culturais - inclusive a si própria -, sendo condição para estabelecimento de relações sociais, articulação e identificação de grupo. A questão vernacular, apesar de não se restringir ao idioma, é fundamentada na dimensão ideológica da língua que atravessa os fatos da história do Brasil.

A chegada dos portugueses ao Brasil transformou radicalmente a ordem social dos autóctones, que gradativamente foram impelidos a integrar um funcionamento cultural no qual seu saber e suas formas de discurso não tinham o mesmo valor. Com os lusitanos, chegaram outros costumes, outras artes, outra organização política, outras leis, outra língua. Mais do que falta de força bélica para combater o povo d'além mar, faltaram armas ideológicas que fizessem frente ao empreendimento europeu. Houve tensão entre o olhar português sobre esta terra e o daqueles que a habitavam. Se o espaço físico era idêntico, o olhar, ideologicamente orientado, diferia em absoluto. Para mencionar o mínimo, o autóctone enxergava a multiplicidade étnico-linguística no vasto espaço geográfico que o português entrevia como unidade colonial.

Resultou daí alteração na condição de sujeito e, portanto, nas possibilidades de construção de identidades coletivas. Para se definir em meio à ordem que se instituía era preciso posicionar-se em relação aos parâmetros 
impostos pelo projeto colonizador. Nesse cenário, a língua portuguesa representava não apenas modificação do código linguístico de comunicação no território em construção, mas acima de tudo mudança da língua de ação política. O funcionamento cultural que se impunha não se permitia reacentuar senão pelo idioma português, que passou a funcionar como condição de participação na dinâmica social. Assim, novos equipamentos linguísticos foram forjados para viabilizar as instituições fundamentadas no paradigma lusitano. Nesse quadro, a escrita em língua portuguesa opera tanto como instrumento ideológico quanto como mecanismo de documentação de valores agregadores de coletividades, atando um nó de questões linguístico-subjetivas que, ao longo da trajetória histórica, constituíram e têm atualizado a memória cultural estruturante da brasilidade.

Assumindo a chegada dos portugueses como marco inicial da historicização do Brasil, parte-se da hipótese de que a escrita histórica e a literária não apenas registram nuanças culturais como também encaminham possibilidades de significá-las, de maneira que, ao longo do tempo, documentos de diferentes esferas manifestam perspectivas constitutivas da heterogênea memória brasileira. O objetivo deste trabalho é demonstrar como escritas de diferentes esferas de circulação e diferentes inserções temporais refletem valores integrantes da memória cultural e refratam juízos determinantes dos discursos que constroem o senso de vernáculo que se define mais pelo embate do que pela convergência ideológica. Para nortear a discussão, levantamse as seguintes perguntas: a) Que lugares sociais as escritas sobre o Brasil deflagram? b) Como a política lusófona corrobora esses lugares sociais? c) De que maneira a significação e ressignificação dos valores constitutivos da memória cultural documentam o vernáculo brasileiro?

O percurso argumentativo deste artigo está organizado em três eixos. No primeiro, discutem-se teoricamente os processos de subjetivação e de identidade coletiva no Brasil e a relevância da língua portuguesa, em especial, da escrita em língua portuguesa na historicização brasileira. No segundo, apresentam-se os critérios de seleção dos dois documentos aqui confrontados - a "Carta" de Pero Vaz de Caminha e o poema "Erro de português", de Oswald de Andrade - e os de delimitação dos aspectos linguísticos, enunciativos e discursivos que atualizam os processos de significação e ressignificação do Brasil. Por fim, no terceiro eixo, analisam-se os documentos a fim de demonstrar como as diferentes instâncias enunciativas capturam a heterogeneidade constitutiva da vernaculidade do Brasil. 


\section{SUBJETIVAÇÃO E IDENTIDADE COLETIVA: CONDIÇÕES DA VERNACULIDADE BRASILEIRA}

Dois processos diferentes, porém relacionados, são decisivos para a construção da vernaculidade. Subjetivaçãa diz respeito aos processos que validam laços sociais e definem a condição de integrante - sujeito - de um grupo. Identidade denota os valores estabilizados provisoriamente na caracterização dos sujeitos. Ambos constituem processos. Todavia, subjetivação aponta para as condições de produção da ordem social, ao passo que identidade aponta para os sentidos projetados sobre a coletividade e sobre aqueles que a constituem. No encontro das relações estruturantes e estruturadas na cultura com os acabamentos identitários significantes do grupo social está a vernaculidade, que permite o coletivo fazer sentido de si. Observe-se cada aspecto separadamente.

A noção de sujeito é atravessada por diversas dimensões, de modo que o vocábulo encerra mais uma discussão do que uma definição precisa. Do ponto de vista filosófico, na metafísica clássica, por exemplo no aristotelismo, o termo designa o ser real, substância, realidade permanente à qual se atribuem transformações. Em uma abordagem epistemológica, especialmente a partir do cartesianismo e do pensamento moderno, sujeito indica o eu pensante, consciência, espírito ou mente enquanto faculdade cognoscente e princípio fundador do conhecimento. Etimologicamente, do latim subjectus, sujeito traz a ideia de "subordinado a", "submetido a", "situado abaixo de". Essa dimensão evidencia uma questão importante: a necessária relação. A construção de um sujeito implica relação. Mesmo da perspectiva cartesiana, em que o ser cognoscente se basta como fonte do conhecimento, o sujeito instaura-se na relação com o conhecimento. Penso, logo existo, mais do que uma frase, implica uma enunciação e, nessa condição, está posta a interação. O espírito ou mente cognoscente flagrado no enunciado se constrói a partir da base relacional. Por conta disso, os sentidos mobilizados etimologicamente valem como mecanismo de abordagem dos processos de subjetivação, isto é, dos processos relacionais por meio dos quais os sujeitos se constroem. Mas quais relações constroem sujeitos e como elas se dão?

A condição de sujeito implica relação em duas instâncias. A instância subjetiva caracteriza-se pela distinção e posicionamento, ao passo que a intersubjetiva define-se pela identificação e compartilhamento. O outro do 
processo relacional localiza-se no plano horizontal no qual se dá o contato dialogal com o semelhante; instância das relações entre sujeitos. Além disso, também dispõe-se assimetricamente num plano vertical, definindo o universo simbólico estruturante das relações identificadas no nível dialogal estrito; instância da relação de sujeito. Para diferenciar tais instâncias, Dufour (2005) retoma a diferenciação entre o termo outro - manifestação da alteridade horizontal no âmbito dialogal - e o termo Outro - referencial de valor instaurador da esfera simbólica vetor da dinâmica cultural.

Elaborada por Lacan em 1955, durante um seminário anual sobre "o eu na teoria de Freud e na técnica da psicanálise”, a distinção Outro/outro caracteriza dois planos de alteridade: o especular, em que o sujeito se define a partir da identificação com seu semelhante, e o simbólico, no qual se estabelece a assimetria determinante da condição de sujeito (Roudinesco \& Plon, 1998). O estádio de espelho configura um momento psíquico e ontológico da evolução humana definidor da relação do sujeito com o outro. Aí articulam-se relações de ordem empírica e de ordem da representação. No plano simbólico, a relação com o Outro escapa às dimensões real e imaginária e constrói o universo de sentido que orienta e determina o sujeito. O grande Outro designa o lugar simbólico a partir do qual se estabelece a hierarquia fonte dos sentidos que conferem ao indivíduo a condição de sujeito (Roudinesco \& Plon, 1998).

Sem negá-la, Dufour (2005) critica os limites estruturalistas da perspectiva psicanalítica e acresce ao par conceitual a preocupação com a historicidade do Outro, trazendo à tona também as dimensões filosófica e sociológica. Partindo da etimologia de sujeito, Dufour (2005) pondera como a assimetria propicia processos de subjetivação. Localizado num plano diferente do do sujeito, o Outro funciona como referencial ao qual é possível submeter-se ou contra o qual se pode rebelar. De qualquer maneira, o Outro permanece como condição de subjetivação.

$\mathrm{O}$ autor argumenta que a filosofia sempre se interessou pelo fato de o humano ser uma substância cuja existência se apoia em outro ser. As diferentes abordagens ontológicas apontam para a constituição do ser a partir da relação. Desde os sofistas, que entendiam a existência como um permanente devir, passando pelos pré-socráticos, que interpretavam como ser primeiro e último a Natureza em sua multiforme manifestação, por Aristóteles, que advogava uma ontologia do concreto, até Kant e sua proposição da Razão 
como princípio supranatural e dado a priori, entre tantas outras abordagens, Dufour (2005) identifica nos exercícios filosóficos formas especulativas de construção do Ser. O autor afirma:

nenhuma [forma especulativa] caminha sem uma política que celebra, organiza ou prepara o reinado do ser nos homens. Nessa medida, toda ontologia é política (...) o Ser, portanto, nunca é puro, possui sempre uma tradução, poderíamos dizer um dublê político. Dublê a quem poderíamos dar o nome de "terceiro" ou de "Um". (Dufour, 2005:28 - grifos do autor)

Esse Um que permeia qualquer abordagem ontológica é dinâmico como a história, o que permite o autor retomar a noção do grande Outro em Lacan para elucidar não apenas o caráter simbólico advogado na Psicanálise como também a natureza política inerente a qualquer apreciação ontológica:

O terceiro, centro dos sistemas simbólico-políticos, tem, portanto, em todos os casos, estrutura de ficção, de ficção sustentada pelo conjunto dos falantes. É por isso que não se pode nunca separar o político de um certo número de mitos, de narrativas e de criações artísticas destinadas a sustentar a ficção. As diferentes narrativas com efeito prescrevem a feição que convém dar ao grande Sujeito para que dois interlocutores possam se dedicar, quase pacificamente, a sua inesgotável vocação, falar, que modela todas as outras atividades (Dufour, 2005:30).

O grande Sujeito, o Um ou o Terceiro configuram modalidade de alteridade instauradora dos sistemas simbólico-políticos constitutivos da história. Contraponham-se, por exemplo, as questões mobilizadas para sustentar a relevância cultural de sistemas de governo como a Monarquia e a República. O reconhecimento pelo grupo da figura do Chefe de Estado e de Governo requer o compartilhamento do referencial axiológico que estrutura o Outro. O respeito ou não à vitaliciedade, à linha sucessória, à justaposição ou separação de Chefe de Estado e de Governo, entre outros aspectos, dependem de "narrativas ficcionais sustentadas pelo conjunto de falantes" (Dufour, 2005:30), ou seja, dependem de discursos fundadores e mantenedores dos laços sociais que unem o coletivo de determinado modo e não de outro. E isso não se dá apenas no nível simbólico, mas também sociológico, e é garantido pela interação verbossocial.

O conceito ampliado de Outro permite analisar e interpretar um importante embate instaurado na historicização do Brasil. No período colonial, a ordem social lusitana conflita com a autóctone, gerando um choque 
de Outros e, portanto, de valores institucionais. No período do Império, consolidam-se as bases do funcionamento europeu, embora alterado pela memória cultural construída desde o Brasil Colônia (Mariani, 2004), em detrimento daquelas que sustentaram os grupos autóctones. Nas fases republicanas, o processo tem seguimento. Conforme as tensões vão sendo geridas sociologicamente, são produzidas cicatrizes simbólicas constitutivas da memória cultural, e tais cicatrizes significam a história. Se participar da ordem social requer compartilhar o referencial que costura a coletividade e se posicionar em relação a ele, os pontos de vista que atualizam a história do Brasil manifestam movimentos axiológicos que encaminham os processos de subjetivação e dão sentido aos fatos políticos. Assim, a vernaculidade no Brasil orienta-se pelas disputas que arranjam grupos sociais e pelos acabamentos sociopolíticos que vão sendo projetados para tais disputas.

Esses acabamentos provisórios dão o contorno das identidades sociais, entendidas como manifestações culturais múltiplas, fluidas, construídas a partir das diversas possibilidades de estabilização das formas de posicionamento no mundo - condição subjetiva (Shotter, 1993; Bakhurst \& Sypnowich, 1995; Sarup, 1996; Castells, 2001). Configuram "processo de construção de significado com base em um atributo cultural, ou ainda um conjunto de atributos culturais inter-relacionados, o(s) qual(is) prevalece $(\mathrm{m})$ sobre outras fontes de significado" (Castells, 2001:22). Não cabe, portanto, rastrear uma identidade estável, e sim "possíveis identidades, como membro de certa cultura, ou de certo grupo socioeconômico” (He, 1995:214 - tradução nossa), e nesse empreendimento, consideram-se três possibilidades de acabamento.

As diferentes condições de produção modelam identidades legitimadoras, de resistência ou de projeto (Castells, 2001). As identidades legitimadoras são ditadas pelas instituições dominantes e visam à manutenção e expansão dos princípios hegemônicos. Ratificam a dominação de uns sobre outros, estratificando as relações do plano dialogal. As identidades de resistência são criadas por aqueles em posição desprestigiada que buscam mitigar o poder. Tais sujeitos procuram estabelecer relações que lhes garantam vez e voz no âmbito cultural. As identidades de projeto consistem na transformação das propostas de resistência em um novo acabamento capaz de redefinir o posicionamento de determinados sujeitos e configuram, desse modo, conquistas daqueles que primeiro se envolveram em lutas por mudanças na sociedade. 
Dessa perspectiva, identidade nacional envolve disputas simbólicoideológicas definidoras dos laços que costuram a ideia de nação e deve ser entendida como construção sócio-histórica. Os sentidos aglutinadores de uma coletividade reconhecida como nação tornam-se fatíveis a partir de valores estruturados no século XVIII e consolidados plenamente no século XIX (Thiesse, 1999; Fiorin, 2009). Então, não é tanto a questão temporal que diferencia a nacionalização brasileira da dos Estados europeus. A peculiaridade da historicização do Brasil está na maneira como a tensão identidade/alteridade fundamenta os laços socioculturais.

O Brasil representou uma das primeiras experiências bem-sucedidas de criar uma nação fora da Europa. A nação é vista como uma comunidade de destino, acima das classes, acima das regiões, acima das raças. Para isso, é preciso adquirir uma consciência de unidade, a identidade, e, ao mesmo tempo, é necessário ter consciência da diferença em relação aos outros, a alteridade. O grande outro [...] da criação da nacionalidade brasileira é Portugal. No entanto, a constituição da nação brasileira apresenta um problema, já que a independência é proclamada por um príncipe português, herdeiro do trono de Portugal. Não houve, portanto, uma ruptura completa com a antiga metrópole. $\mathrm{O}$ trabalho de construção da nacionalidade começa, então, com a nacionalização do monarca. Pedro I é mostrado como alguém que renuncia a Portugal e assume a nacionalidade brasileira. (Fiorin, 2009:117)

Retrospectivamente, o ato deflagrador da nacionalização evidencia como a ideia de Brasil tem início com o empreendimento colonizador, que projeta unidade à multiplicidade ali existente. Prospectivamente, o ato deflagra o desafio de significar as particularidades culturais da coletividade que se organiza. A(s) identidade(s) brasileira(s) deve(m), portanto, abarcar os jogos estabelecidos entre sujeitos construídos, desconstruídos e articulados pela legitimação, resistência e/ou projeto ao longo da história, e a vernaculidade deve ser investigada a partir dos processos de subjetivação e de identidade nacional. Não há como desenvolver o senso de pertença, o reconhecimento de algo próprio do Brasil, sem enfrentar o desafio de ser sujeito e de se identificar como coletividade. Nessa trama, a política lusófona merece destaque. Se para Portugal a língua identifica a nação lusitana e corrobora seus laços sociais, para o Brasil, impinge um traço de alteridade na gênese da identidade nacional. Eis aí importante nó para a construção vernacular. 


\section{A política lusófona e A QUeStão do vernáculo no e do Brasil}

Para entender como a política lusófona no Brasil institui uma língua nacional e encaminha a possibilidade de definição de um senso vernáculo, é importante destacar a concepção de língua que atravessa esta reflexão. Neste artigo, entende-se que a língua, tal como discutem Voloshinov ${ }^{1}$ (1988) e Bakhtin/Volochínov (1999), resulta da atividade coletiva - portanto, atrela-se à organização cultural, e não à expressão individual - e em todos os seus elementos espelha e altera a organização da coletividade que a levanta - ou seja, não se separa do universo simbólico e político em que se produz. Assim, é possível dizer que a língua portuguesa no Brasil espelha e altera o funcionamento cultural que se estabelece a partir da colonização, não sendo válida a ideia de simples transposição do idioma lusitano. A colonização desenvolve uma política lusófona determinante para a historicização brasileira, mas a língua portuguesa no Brasil necessariamente manifesta traços do Brasil.

Mariani (2004) discute como a política linguística da Coroa Portuguesa mudou o contexto de línguas na então Colônia até que o português assumisse não apenas prestígio cultural, mas principalmente status de língua do Brasil. No período colonial, o quadro de línguas era bem complexo. Grosso modo, ao longo da costa brasileira o português desenvolvia-se razoavelmente, ao passo que, no interior, entre as centenas de línguas indígenas, estabilizavam-se duas línguas francas de base tupinambá: a língua geral amazônica e a língua geral paulista (Noll, 2010). Comunicativamente, o português não tinha, a princípio, tanto prestígio, já que a população indígena sobrepujava a lusófona. A catequese exercida pelos jesuítas em "língua brasílica" ratifica isso. Culturalmente, porém, com a imposição da ordem social portuguesa, a língua lusitana suplanta todas as demais até se instituir como língua nacional. Ações políticas concretas, como a promulgação do Diretório dos Índios, em 1757, na gestão pombalina, foram determinantes para a definição linguística brasileira. Mariani (2004) demonstra como, a partir dessas ações, a língua lusitana constrói uma memória diferente daquela estabelecida na Europa e, assim, atualiza o que denomina colonização linguística.

1. Mantém-se a grafia do nome do autor conforme a edição consultada. 
Neste artigo, interessa recuperar a trama enunciativa via língua portuguesa, mais especificamente via escrita em língua portuguesa, que espelha e altera os sentidos de Brasil, de maneira a construir uma memória cultural válida para a coletividade a ponto de se reconhecer um acabamento vernáculo. Para isso, rastreia-se a política inerente à língua portuguesa - o caráter necessariamente ideológico do idioma - e detectam-se os pontos de vista que realizam os processos de subjetivação e permitem a construção de identidade(s) brasileira(s).

Entendendo por ideologia "a totalidade de reflexões e refrações no cérebro humano da realidade social e natural, tal como expressa e fixada pelo homem [sic] na palavra, desenho, diagrama ou outra forma de signo" (Voloshinov, 1988:113 - grifos da edição consultada; tradução nossa), verifica-se a interpenetração língua/sujeito/cultura como a base enunciativa da política linguística aqui discutida. Assim, para fins estritamente argumentativos, propõe-se a distinção de dois planos por meio dos quais é possível descrever a retroalimentação entre língua, sujeitos e funcionamento cultural. O primeiro diz respeito à natureza dialogal do sistema linguístico. Independente das coerções históricas, qualquer enunciado mobiliza um código e opera com mecanismos de atualização da subjetividade pela intersubjetividade. Em outras palavras, não há como subtrair-se da linguagem.

Eu só pode ser identificado pela instância de discurso que o contém e somente por aí. Não tem valor a não ser na instância na qual é produzido. Paralelamente, porém, é também enquanto instância de forma eu que deve ser tomado; a forma eu só tem existência linguística no ato de palavras que a profere. Há, pois, nesse processo uma dupla instância conjugada: instância de eu como referente, e instância de discurso contendo eu, como referido. A definição pode, então, precisar-se assim: eu é o "indivíduo que enuncia a presente instância de discurso que contém a instância linguística eu". Consequentemente, introduzindo-se a situação de "alocução", obtém-se uma definição simétrica para tu, como "indivíduo alocutado na presente instância de discurso contendo a instância linguística tu”. Essas definições visam eu e tu como uma categoria da linguagem e se relacionam com a sua posição na linguagem (Benveniste, 2005:278, 279 - grifos da edição consultada).

$E u$ e $t u$ constituem manifestações na língua das relações intersubjetivas. Eu, como locutor, atualiza a posição daquele que mobiliza a língua e tu, como alocutado, a posição daquele interpelado pela língua. Na trama locucional, as posições de sujeitos marcam tanto os referentes na enunciação quanto os referidos. O referente aponta para a circunscrição situacional, 
enquanto o referido esbarra nas dimensões simbólicas e sociológicas, o que permite identificar $e u$ e $t u$ como marcas formais de categorias linguísticoenunciativo-discursivas.

O segundo plano proposto diz respeito à natureza dialógica da língua e às manifestações de relações subjetivas. Seja qual for a instância enunciativa, há o enquadre ideológico que torna a comunicação inteligível. Em última instância, é o eixo axiológico compartilhado pelos indivíduos - o Outro que os torna sujeitos habilitados a significar pela língua. Como afirmam Bakhtin/Volochínov (1999:35),

não basta colocar face a face dois homo sapiens quaisquer para que os signos se constituam. É fundamental que esses dois indivíduos estejam socialmente organizados, que formem um grupo (uma unidade social): só assim o sistema de signos pode constituir-se (grifos da edição consultada).

No enunciado, fica evidente como língua, sujeito e cultura encontramse necessariamente inter-relacionados pelos laços tecidos na ideologia. $\mathrm{O}$ plano dialogal serve como construto teórico de acesso a marcas formais, e o plano dialógico, como categoria de interpretação das coerções simbólicoideológicas da língua. O todo do fenômeno enunciativo aqui tratado se dá no necessário encontro do acabamento estético - mobilização material formal - e da responsabilidade ética - condição sócio-histórica de qualquer manifestação da linguagem. De outra maneira, recuperar-se-iam atividades de dois ou mais homo sapiens, mas não de um grupo social.

Dessa perspectiva, a língua portuguesa transforma as possibilidades comunicativas e, principalmente, altera o lugar social do qual a cultura é significada na historicização do Brasil (Magalhães, 2012). O projeto colonial impõe nova ordem, de maneira que as ações na sociedade passam a ser mediadas preponderantemente pelo idioma lusitano. A visão de Brasil como territorialidade, como unidade política consolida-se via língua portuguesa. A partir daí, são lançadas as bases de legitimação, e os movimentos de resistência ou de projeto significam e têm força social se realizados em português. A língua portuguesa no Brasil constitui, portanto, pilar de encaminhamento de um vernáculo do Brasil.

A política lusófona tem o sucesso garantido pela destacada assimetria entre o status do português e o das línguas dos autóctones no período colonial. As línguas ágrafas dos indígenas não podiam fazer frente à única língua 
daquele contexto equipada para cumprir as funções instituídas e valoradas na ordem imposta pelos colonizadores. Nesse cenário, mais do que uma técnica, a escrita constitui instrumento de significação e ação cultural e institui equipamento (Calvet, 2007) para construção vernacular brasileira.

A produção escrita dispõe o funcionamento cultural arquitetado num fluxo ideológico diferente daquele que orientava a ordem social antes da chegada lusitana. Como afirmam os pensadores russos, "o discurso escrito é de certa maneira parte integrante de uma discussão ideológica em grande escala: ele responde a alguma coisa, refuta, confirma, antecipa as respostas e objeções potenciais, procura apoio etc." (Bakhtin/Volochínov, 1999:123). A princípio, a escrita no Brasil responde, refuta, retoma questões de outro lugar, e à medida que os documentos produzidos vão tecendo uma cadeia comunicativa específica, as questões passam a ser vernáculas, donde se reconhece uma escrita do Brasil.

$\mathrm{Na}$ condição de equipamento da política lusófona, a escrita opera, então, como vetor de subjetivação e de identidade nacional, como gatilho de transformação social, e dois aspectos interdependentes são fundamentais: o arquivo e a memória. A materialidade da escrita permite o registro de ideias que podem ser significadas a cada trama enunciativa envolta no documento escrito. Esse aspecto faz dela um mecanismo de arquivo que estabiliza a potencialidade do documento de significar. Não registra sentidos, porque estes não se deixam capturar a ponto de tornarem-se imanentes ao escrito, mas arquiva a potencialidade semântica de ideias enunciadas que podem ser assimiladas, reorganizadas e reacentuadas em outro tempo, outro lugar, por outros sujeitos. O caráter documental da escrita promove o rearranjo das relações intersubjetivas do enunciado, uma vez que os referentes cristalizam-se, mas os referidos podem ser ressignificados de acordo com a esfera cultural em que é atualizado. Escritura e reescritura, leitura e releitura compartilham um mesmo arquivo, um mesmo registro, mas atualizam processos singulares. A folha de papel, o livro, o manuscrito etc. podem manter-se, porém, o enunciado transforma-se conforme a dinâmica sócio-histórica que interpela o arquivo.

Discutindo o impacto das tecnologias da memória - a saber, a escrita e a informática - na cultura e no posicionamento dos sujeitos, Amorim (2009) demonstra como a escrita altera relações e influencia a ordem social ao refletir sobre a relação entre corpo, conhecimento e memória 
culturais. De acordo com a autora, a democratização da escrita transforma os mecanismos de transmissão dos valores sociais e, consequentemente, o funcionamento do grupo.

Nas sociedades de tradição oral, os saberes coletivos se atualizavam no corpo do sujeito singular, fosse pela escrita no corpo, como no caso das pinturas indígenas, fosse pela fala e pelo relato. Os saberes passavam pelo corpo singular, não de modo individual e isolado, mas tornando esse sujeito responsável e participante ativo do manter viva a memória do grupo pela sua incessante transmissão. Do mesmo modo, o destinatário dessa transmissão a acolhia e lhe respondia de corpo inteiro. Estávamos aí em uma situação enunciativa de co-presença. Com a invenção e a democratização da escrita, esta se constitui em uma técnica que traz uma novidade radical: a memória se externaliza e como que sai do corpo do sujeito, da pele ou da voz, para se instalar em algo de fixo e material separado dele - a página escrita e o livro. A técnica mnemônica da escrita transforma o lugar do sujeito no grupo quanto a sua responsabilidade de portador - aquele que recebe, conduz e transmite os saberes coletivos. (Amorim, 2009:15)

No âmbito do funcionamento cultural, a escrita pode promover relações intersubjetivas sem necessariamente mobilizar o indivíduo, uma vez que atualiza a memória objetiva - aquela registrada nas línguas, nos gêneros do discurso, nos rituais, enfim, na cultura - e não somente a subjetiva - aquela que atravessa os responsáveis pela transmissão do saber (Bakhtin, 2002; 2010; Amorim, 2009). No caso dos documentos que perduram por séculos, a interação que medeiam envolve um jogo de memórias: a subjetiva, que atualiza o repertório dos implicados no enunciado, e a memória objetiva, encorpada pelos múltiplos estratos semânticos estabelecidos a partir da potencialidade documental (Magalhães, 2011). As escritas do Brasil, portanto, guardam fragmentos da memória objetiva cultural e, por isso, instigam, desafiam, coadunam-se, alteram a memória dos sujeitos que se lançam em diálogo a partir dos arquivos. Dessa maneira, a escrita no Brasil leva a cabo a política lusófona que interpela os processos de subjetivação e de identidade nacional e corrobora a configuração de um vernáculo do Brasil.

\section{SELEÇÃO DE DOCUMENTOS, DELIMITAÇÃO DE FOCO E ROTEIRO DE} ABORDAGEM

Neste artigo, foram selecionados dois documentos de envergadura cultural: a "Carta" de Pero Vaz de Caminha e o poema "Erro de português", 
de Oswald de Andrade. O primeiro consiste de uma escrita histórica que registra importante alteração acerca do saber sobre o mundo. Apesar das evidências e registros de passagens anteriores dos europeus pelo chamado "mundo novo", essas terras ainda eram um mundo parcialmente desconhecido. Diante de incertezas geográficas, a "Carta" testemunha a existência do "novo" mundo e reacentua o discurso sobre ele ao desmistificá-lo por meio do relato oficial.

Do ponto de vista linguístico, o texto se insere na chamada época histórica, mais especificamente na transição entre o que se reconhece como período arcaico e moderno do português (Câmara Junior, 1975; Coutinho, 2005; Hauy, 2008). Nesse período, o idioma se separa do galego, constituindo importante arquivo referencial identitário para Portugal. A presença da língua fora da Europa agrega à sua história outros contornos socioculturais, e o documento de Caminha registra também este aspecto do percurso de definição da língua nacional lusitana.

Assim, a "Carta" opera como escrita histórica - porque integra o fluxo de ações políticas constitutivas de Portugal e mobiliza movimentos linguísticos relevantes para a identidade nacional lusitana - e funciona como escrita fundadora - porque vislumbra o Brasil antes de este sê-lo, projetando uma percepção territorial pelo estranhamento cultural. O texto de Pero Vaz recolhe em discurso escrito os atos empíricos de execução do empreendimento da Coroa Portuguesa e faz bem mais do que listar fatos. Simultaneamente documenta o projeto colonizador que empreende uma unidade política onde havia multiplicidade étnica, religiosa, linguística etc. e inaugura uma perspectiva da qual o que viria a constituir o Brasil pode ser significado. Por isso, a "Carta" é tomada como escrita primeira da brasilidade.

O segundo documento selecionado, o poema "Erro de português", criado quatro séculos após a redação da "Carta", insere-se no movimento cultural modernista, cujo projeto estético e comprometimento ético visavam à consolidação da arte brasileira propriamente dita, simbólica e politicamente autêntica, desprendida (embora não alheia a) dos modelos europeus. Trata-se de um movimento que favorecia o delineamento de identidades de resistência e de projeto. Como enunciado participante do âmbito literário, o poema dialoga com a historicização brasileira, procurando garantir um lugar social para a identidade de Brasil. Funciona como escrita avaliativa 
de outra, porque constitui crítica à "Carta", e, por isso, é tomada como escrita segunda da brasilidade. O poema apresenta ainda uma peculiaridade pertinente. Sua criação data de 1925, ano em que Oswald de Andrade publica o livro de poemas Pau Brasil. Como o próprio título sugere, é uma obra orientada para a consolidação de uma estética própria do Brasil. O poema circula, porém, em outros projetos editoriais de maneira restrita e pública. Uma versão manuscrita aparece como dedicatória para Jayme da Silva Telles na folha de rosto do Primeiro caderno do alumno de poesia Oswald de Andrade, de 1927, e só será publicado em Poesias reunidas, em 1945 (Himmelseher \& Isensee, 2011). Neste trabalho, acolhe-se a versão manuscrita por conta da especificidade ético-estética de circulação do texto que mobiliza simultaneamente a vida - dedicatória - e a arte - poema.

O arranjo ordinal - escrita primeira e segunda - não diz respeito somente à sequencialidade. A designação se deve à natureza dos discursos constitutivos de cada um. A "Carta" funciona como enunciado inaugural de um projeto sócio-histórico e constitui referencial discursivo que deflagra possibilidades de fazer sentido do Brasil. $\mathrm{O}$ caráter fundador garante ao documento relevância histórica e cultural com influência direta para subjetivação e identidade brasileira nas diversas instâncias em que se manifestam. O poema sopesa o enunciado fundador e significa como discurso sobre discurso. As duas esferas dos documentos selecionados - histórica e literária - não se fundem nem se confundem; funcionam por referenciais éticos diferentes que se coadunam quanto à relevância para a discursivização do Brasil. Os textos nas diferentes esferas só fazem sentido por operarem com valores socialmente latentes.

Para alcançar o objetivo de demonstrar como tais escritas refletem valores integrantes da memória cultural brasileira e refratam apreciações definidoras dos discursos que constroem o senso de vernáculo, propõe-se o seguinte roteiro de análise: no primeiro documento, destacam-se índices dos sujeitos em interação e notas interpretativas que revelam fronteiras ideológicas entre acabamento cultural autóctone e europeu; no segundo, são focados elementos léxico-gramaticais de retomada da "Carta" e índices do juízo sobre a "Carta". As marcas das relações dialogais funcionam como categorias de análise linguístico-enunciativa dos documentos, e as dialógicas operam como categorias de interpretação da dimensão discursivo-ideológica dos enunciados atualizados nas produções escritas. 


\section{Primeiro, a escrita de um Brasil}

Para guiar o percurso de leitura e análise proposto, retomam-se as perguntas norteadoras da discussão: a "Carta" de Pero Vaz de Caminha deflagra que lugares sociais para sujeitos no Brasil? Como a política lusófona inerente à "Carta" corrobora esses lugares sociais? De que maneira a potencialidade semântica da "Carta" fundamenta a memória cultural e lança bases para a construção de um vernáculo brasileiro?

O primeiro procedimento de análise leva em conta as relações de pessoa na língua para rastrear as posições subjetivas em interação. Pero Vaz de Caminha, escrivão da feitoria de Calecut, e D. Manuel, Rei de Portugal, são, respectivamente, remetente e destinatário do documento. Enviado pelo monarca na armada de Pedro Álvares Cabral, Caminha era responsável por registrar os acontecimentos da jornada, o que implicava dispor fatos em discurso escrito. $\mathrm{Na}$ "Carta", interligam-se o empreendimento da armada de conquistar terras e o fluxo comunicativo do escrivão para deixar o monarca a par dos acontecimentos. Se há evidência do interesse português em sondar os riscos militares de estabelecer contato comercial e religioso com o Oriente, não há consenso entre historiadores se o afastamento para oeste e o alcance da "Ilha de Vera Cruz" foram propositais (Lopez \& Mota, 2008; Boris, 2010; Del Priore \& Venancio, 2010). A intenção não pode ser determinada, mas a intencionalidade colonizadora está manifesta no projeto enunciativo. Observe-se a abertura da "Carta"2:

\section{Snõr}

posto que o capitam moor desta vossa frota e asy os / outros capitaães screpuam a vossa alteza a noua do acha / mento desta vossa terra noua que se ora neesta naue / gaçom achou, nom leixarey tambem de dar disso / minha comta a vossa alteza asy como eu milhor / poder ajmda que pera o bem contar e falar o saiba / pior que todos fazer, pero tome vossa alteza minha / jnoramçia por boa comtade, a qual bem çerto crea que / por afremosentar nem afear aja aquy de poer ma / is ca aquilo que vy e me pareçeo. // da marinha / jem e simgraduras do caminho nõ darey aquy cõ / ta a vossa alteza porque o nom saberey fazer e os / pilotos deuem teer ese cuidado e por tamto Snõr / do que ey de falar começo e diguo. / (Caminha, 1500:1)

A trama dialogal instaurada evidencia a dimensão política do "achamento” da terra. As relações de pessoa estabelecidas nesse fragmento e a

2. Citada conforme ortografia e marcação de linhas e parágrafos do documento consultado. 
escolha lexical para designar a chegada da armada sinalizam a perspectiva da qual o acontecimento é significado. A interação entre Pero Vaz e D. Manuel é culturalmente acabada como diálogo entre escrivão e Monarca. A figura do Rei D. Manuel personifica a manifestação de desígnios do Deus cristão, legitima as relações subjetivas e regula as relações sociais intersubjetivas na coletividade lusitana. Nesse universo simbólico-político, Monarquia e Cristianismo (Catolicismo Romano) são chave para o processo de significação da "Carta".

No mesmo trecho, o uso do pronome possessivo de segunda pessoa marca as relações de pessoa. A instância "vossa terra noua" destaca-se não só como evidência linguística da consolidação do idioma lusitano, mas acima de tudo como índice simbólico-cultural. Na história interna da língua portuguesa, vossa vem de vostra (por vestra). A forma vostram documentada no latim arcaico pode ter se conservado na linguagem popular, resultando no pronome vossa (Coutinho, 2005:259). Admite-se também que vostram seja uma forma criada por analogia com nostram (Nunes, 1989:244-245; Coutinho, 2005:259; Hauy, 2008:74-75, entre outros). Independente da explicação para a formação diacrônica do vocábulo, vossa constitui uma formação vernácula lusitana e importa reconhecer no uso o valor social que a atravessa.

Vossa terra noua trata-se de um sintagma nominal cujo núcleo - o substantivo terra - é determinado pelo pronome possessivo feminino de segunda pessoa do plural vossa e modificado pelo adjetivo noua. Linguisticamente, cada elemento tem sua contribuição sintático-semântica, de maneira que ali se recuperam os seguintes traços: 1) referência ao espaço físico: terra; 2) identificação do possuidor, a pessoa com que se fala: vossa; 3) atributo do referente: nova. Discursivamente, o sintagma mobiliza o lugar social a partir do qual aquilo que se constituirá como Brasil é significado: o elemento 1 designa o espaço físico alcançado pela armada; o elemento 2 confere-lhe valor político, e o 3 denota o marco histórico que altera o valor cultural daquele espaço físico. A terra como empiria não foi modificada para que se denominasse nova; como elemento simbólico, porém, já não era a mesma de antes da chegada dos portugueses. O marco histórico fundador significado no documento viabiliza tal qualificação.

Também o registro "achamento" corrobora o olhar político-cultural sobre a terra. $\mathrm{O}$ que foi alcançado pelos portugueses não era inabitado. 
Muito pelo contrário, ali havia diversidade étnico-cultural. Pesquisas indicam que os primeiros habitantes do território atualmente correspondente ao Brasil chegaram a essa porção de terra há aproximadamente 20 mil anos e, embora não haja consenso acerca de sua origem, acredita-se que tenham vindo da Ásia, da Austrália, da Melanésia e de outras partes da Oceania (Lopez \& Mota, 2008). Todavia, os lusitanos contemplam em sua chegada agrupamentos falhos, lacunares, nos quais faltam os elementos referenciais do que conheciam e concebiam como civilização. A diversidade autóctone foi assumida como ádvena, estranha, fora do padrão. Sendo assim, o termo achamento traduz o marco histórico-ideológico a partir do qual aquela porção de terra é significada, e a escrita da "Carta" registra esse ponto de vista semântica, histórica e culturalmente.

A nomeação escrita da chegada dos portugueses deixa evidentes os sentidos fundamentais para a historicização da terra a partir daí. A postura manifesta em "achamento desta vossa [do rei de Portugal] terra noua" desconsidera os sentidos que até então possam ter sustentado e mobilizado a ordem social, forjando um enunciado fundador da história daquele lugar; nova seria a história a ser contada a partir de então. O encerramento do texto ratifica esse processo de significação: "deste porto seguro da vosa jlha da vera cruz oje / sesta feira prim. ${ }^{\circ}$ dia de mayo de 1500" (Caminha, 1500:27 grifos nossos). Na datação da "Carta”, a "terra noua" está designada "jlha da vera cruz" cuja posse é mais uma vez creditada ao rei. O pensamento cristão e o valor monárquico operam como abscissa e coordenada determinantes do quadrante em que se instauram os sujeitos em diálogo no documento e configuram sua matriz enunciativo-semântica.

O universo simbólico-político resgatado na escrita histórica fundadora do processo de significação do Brasil não deve ser ingenuamente interpretado como uma esfera de sentido imune à realidade social com que se depara. O contato entre línguas, povos, culturas altera o lugar e o ponto de vista também daquele que se impõe. Mesmo com uma ordem sobrepujando outra, a tensão não se resolve pelo simples apagamento do dominado e seu Outro.

(...) e o capitam man / dou no batel em terra nicolaao coelho pera veer aqle / Rio e tanto que ele comecou pera la dhir acodirã / pel praya homeës quando dous quando tres / de maneira que quando o batel chegou aa boca / do Rio heram aly xbiij ou $\mathrm{xx}$ homeës pardos / todos nuus sem nenhuüa cousa que cobrisse suas / vergonhas. traziam arcos nas maãos e suas see / tas. vijnham todos Rijos pera o batel e nicolaao 
co / elho lhes fez sinal que posessem os arcos, e eles os / poseram. aly nom pode deles auer fala nem antë / dimento que aproueitasse polo mar quebrar na / costa. soomente deulhes huum barete vermelho e / huủa carapuça de linho que leuaua na cabeça / e huủ sombreiro preto. E huủ deles lhe deu huủ | sombreiro de penas daues compridas com huủa / copezinha pequena de penas vermelhas e pardas coma / de papagayo e outro lhe deu huü ramal grande / de comtinhas brancas meudas que querem pareçer / daljaueira asquaes peças creo que o capitam / manda a vossa alteza (...) (Caminha, 1500:2-3)

Nesse trecho, está inscrita a primeira tentativa de contato intercultural. Mariani (2004:46-47) destaca aí dois eixos de sentido importantes para o projeto discursivo da "Carta": o do desentendimento - a fala que não se pode aproveitar "polo mar quebrar na costa" - e o do entendimento - a interpelação gestual do português e a resposta indígena. O que se ressalta aqui, não obstante, é o contraponto entre o alinhamento relacional representado pela escrita e aquele atualizado por ela. A fala que não se aproveita e a troca de objetos descrevem os primeiros gestos entre culturas, e o registro escrito desses gestos reconfigura a matriz semântica do funcionamento cultural. O diálogo entre escrivão e monarca toma o autóctone como motivo e representa o contato pelo alinhamento relacional que dá direito de resposta ao indígena, embora não lhe dê chance de ação sobre o direcionamento de sua história. Na dimensão representada, a fala não se aproveita, mas o gesto de doar é correspondido pelo aborígene, que integra o plano dialogal, sem, no entanto, poder interpelar as diretrizes dos colonizadores. $\mathrm{Na}$ dimensão representante, a língua portuguesa e o discurso escrito ratificam os sujeitos de fato actantes, a saber, os portugueses. Pode-se dizer que a escrita - e não o mar que quebra na costa - inviabiliza o aproveitamento da "fala" por parte dos autóctones e inscreve o diálogo no fluxo comunicativo do empreendimento lusitano. Aí se atualiza uma política lusófona que prevê o idioma português e seus equipamentos - no caso, a escrita - como condição de definição, reconhecimento e participação na dinâmica social.

O alinhamento relacional entretecido no plano dialógico, diferentemente, sugere a interferência do autóctone nas ações intersubjetivas. Chamie (2002) propõe uma leitura antropofágica da "Carta”, a partir da qual o olhar surpreso dos europeus e o dos autóctones se interpenetram e se alteram. Isso está manifesto, por exemplo, na atitude exclamativa portuguesa diante do que encontram. 
a feiçam deles he seerem pardos maneira dauerme / lhados de boõs Rostros e boos narizes bem feitos. am / dam nuus sem nenhuủa cubertura nem estimam ne / nhuüa coussa cobrir nem mostrar suas vergonhas, e / estam açerqua disso com tamta jnocemçia como / teem em mostrar o Rostro. traziam ambos os beiços / de baixo furados e metidos per eles senhos osos / doso bramcos de compridam d huüa maão travessa / e de grosura d huủ fuso dalgodam e agudo na põta / coma furador. metemnos pela parte de dentro do bei / ço e o que lhe fica antre o beiço e os demtes he feito / coma Roque denxadrez e em tal maneira o trazem / aly encaxado que lhes nom da paixã nem lhes tor / ua a fala nem comer nem beber. (Caminha, 1500:4)

Nesse trecho está a segunda das seis menções à nudez indígena. A repetição insistente sugere a surpresa do chamado homem branco, interpelado por uma cultura arquitetada em torno de um Outro estranho a ele. A retomada do assunto excede a tarefa estrita de relatar e deixa transparecer um sujeito alterado pela diferença do outro. Se, por um lado, o índio não tem vez nem voz para subverter o empreendimento português, por outro, sua autenticidade deixa patente um acabamento cultural diverso. Ainda que não mude o Outro legitimador europeu, o universo autóctone altera o olhar lusitano, que precisa lidar com fronteiras simbólicas.

A "Carta" e os sentidos nela mobilizados flagram um conflito subjetivo e instauram tensão intersubjetiva. O estranhamento manifesto dialogalmente entre indígenas e portugueses evidencia um choque de referenciais simbólicos e políticos reguladores de ordens sociais diversas. Desse choque resultam dois olhares dialogicamente alterados e um projeto colonizador que não escapa aos sentidos ali deflagrados. Nesse cenário, política lusitana e lusófona estão amalgamadas; por isso, a escrita da "Carta" tanto registra valores como os constrói. A partir dessa escrita em língua portuguesa estabelece-se um lugar social do qual se faz sentido de um Brasil que fomentaria a memória cultural determinante dos sentidos do Brasil - condição para fundamentar um senso de vernáculo.

\section{DePOIS, A ESCRITA DO BRASIL}

Lançadas as bases simbólicas, políticas e linguísticas da escrita na historicização do Brasil, deflagra-se um processo de construção da memória cultural reguladora da negociação do vernáculo. $\mathrm{Na}$ condição de nicho discursivo instituído em língua portuguesa que vincula objetos, costumes 
até instituições à identidade do grupo social, essa memória garante potencialidade semântica aos processos e produtos que se sustentam no nível da coletividade. Sendo dinâmica, a memória se atualiza por meio das apreciações projetadas sobre os laços que unem o grupo social. Cada vez que os sentidos determinantes do grupo são ressignificados, a memória cultural é enriquecida com novos olhares, com lugares sociais dos quais o coletivo é identificado e se identifica. Por isso, as relações que elegem como objeto aspectos da memória cultural alteram-na e integram um diálogo mais abrangente do que os processos interacionais imediatos.

Para dar continuidade à análise das escritas da brasilidade no processo de construção do vernáculo, retomam-se as perguntas norteadoras: como o poema/dedicatória "Erro de português", de Oswald de Andrade, altera os lugares sociais possíveis para os sujeitos no Brasil? Como essa alteração interfere na política lusófona? De que maneira a potencialidade semântica do poema reflete e refrata a memória cultural e documenta o vernáculo brasileiro?

\section{Erro de portuguez}

Quando o portuguez chegou

Debaixo de uma bruta chuva

Vestiu o índio

Que pena!

Fosse uma manhã de sol

$\mathrm{O}$ indio

Teria despido

O portuguez

Oswald de Andrade 1927

(Himmelseher \& Isensee, 2011)

Destacam-se dois eixos semânticos: o da factualidade, que retoma a escrita primeira, e o da contrafactualidade, que a avalia. A distinção é marcada pela organização sintática de cada um. A oração subordinada adverbial que abre o poema localiza a referência de tempo do fato declarado no terceiro verso. O tempo verbal no período situa o momento de ocorrência no passado, e a memória cultural garante a referência histórica. O segundo verso convoca notas descritivas da "Carta", ratificando a referência factual e 
simbólica: "a noute segujmte ventou tamto sueste com chuuaçeiros / que fez caçar as naaos e especialmente a capita / na” (Caminha, 1500:3). A retomada de uma nota descritiva convoca o caráter documental da escrita primeira. Entretanto, o projeto discursivo do poema não se restringe a reescrever o relato. O quarto verso sinaliza a mudança discursiva. Cessa a retomada histórica e se explicita a avaliação. Na sequência, há uma oração condicional contrafactual cuja prótase positiva apresenta um fato com polaridade negativa: não era uma manhã de sol; e cuja apódose positiva articula um conteúdo asseverado negativo: o índio não vestiu o português. A oração condicional sinaliza reconhecimento do legado simbólico, e a avaliação que realiza empreende resistência a essa herança.

Importantes relações de pessoa posicionam os sujeitos ali implicados: tanto lusitanos como indígenas são terceira pessoa. Os outros portugueses (Outro/outro) não têm fôlego matricial como na "Carta", e também não se assumem os mitos indígenas e suas instituições como legitimadores dos sentidos decisivos da brasilidade. O documento se estrutura sobre o patamar alterado simbólica e politicamente pela colonização e sinaliza a singularidade do acabamento cultural brasileiro. O poema registra, então, um lugar social de uma organização coletiva diversa daquelas mencionadas e mobilizante de acabamentos identitários de resistência, que manifestam o vernáculo.

O poema e a "Carta" diferem claramente quanto ao lugar ideológico do qual cada um é constituído, mas há um importante ponto em comum entre ambos: a língua que faz sentido do projeto cultural. Se as condições de produção do relato de Caminha não preveem uma coletividade brasileira - os índios não se definiam como unidade cultural e os portugueses não enxergavam na unidade político-econômica que projetavam um acabamento cultural do qual eles mesmos ou os indígenas fizessem efetivamente parte -, as do poema definem-se num universo político já marcadamente do Brasil.

Quando o escrivão Pero Vaz de Caminha relata a chegada lusitana às terras até então não claramente incluídas no mapa mundi, registra-se o rearranjo do saber geopolítico que inscreve, na história, o rumo do que se constrói. Consequentemente, é dado início à historicização do Brasil; a "Carta" documenta essa fundação e estabelece relações subjetivas e intersubjetivas mediadas pela língua portuguesa no Brasil. É certo que ali 
não havia de fato o Brasil, mas a escrita primeira projeta um acabamento social imprescindível para consolidação da brasilidade e abre caminho para uma política lusófona em prol do empreendimento lusitano. Em meio ao movimento modernista, em 1925, quando Oswald de Andrade cria o poema "Erro de portuguez", laços sociais já consolidaram politicamente o universo brasileiro e a língua portuguesa se instituíra como condição de atualização identitária. O Brasil herda a língua, assume-a como idioma nacional e inscreve nela a organização social, política e econômica daquele espaço, interpenetrando memória cultural e língua portuguesa do Brasil. A alteração do caráter locativo em favor do genitivo é condição para que o idioma participe dos processos de subjetivação determinantes das identidades brasileiras possíveis. Dessa perspectiva ideológica, indio e portuguez figuram como estratos identitários e não como atualizações da brasilidade, por isso, são posicionados como terceira pessoa da trama relacional do poema. O eu que se enuncia não compartilha dos mesmos laços culturais de um nem de outro, de modo a se inscrever em um arranjo coletivo diverso e a se identificar pela resistência. O poema opera com um Outro regulador das relações próprias dessa terra alterada.

O título do poema recolhe metonimicamente o juízo singular que mobiliza a memória cultural brasileira. O substantivo erro carrega, semanticamente, a apreciação negativa sobre o objeto e funciona, sintaticamente, como nome valencial do argumento realizado pelo sintagma preposicionado de portuguez. A função designativa do predicador aponta para um referencial ético específico, e o papel semântico do argumento mobiliza dois processos de significação. A preposição de estabelece uma relação de execução. Nesse caso, portuguez atualiza o agente, creditando ao povo lusitano a responsabilidade sobre o erro. Mas a mesma preposição também pode introduzir uma classificação, o detalhamento da natureza do nome valencial. Nesse outro caso, portuguez não é agente, pelo contrário, é o objeto afetado: o idioma lusitano deturpado, por assim dizer. No título, mantêm-se os dois processos de significação. Na trajetória de sentido realizada ao longo do poema, porém, referenda-se o caráter agente do argumento, restringindo a potencialidade semântica do texto ao eixo da historicização do Brasil. O jogo de ampliação e delimitação de sentido estabelecido entre título e corpo do poema dá ao acabamento ético-estético do enunciado um tom avaliativo irreverente. Discursivamente, recupera-se nesse jogo um posicionamento social que faz sentido de um espaço simbólico historicamente vinculado ao povo lusitano e politicamente derivado de um equívoco. 
Isso a um só tempo; a memória cultural convocada opera pelo amálgama dessas dimensões históricas e políticas específicas, de maneira que a crítica sobre as ações lusitanas é acrescida ao senso coletivo brasileiro sem adesão à perspectiva indígena.

Outro importante aspecto constitutivo do tom valorativo do poema é a esfera de circulação da qual é recuperado. Em 1927, dois anos após sua criação, a versão manuscrita circula como dedicatória na folha de rosto de outro livro do poeta: Primeiro caderno do alumno de poesia Oswald de Andrade. A obra dedicada assemelha-se a um caderno escolar de poesias. Apresenta caricaturas ao lado dos textos, esboços que indicam raciocínio, hesitação etc. O poema transcrito figura como mais um rabisco, mais uma anotação e assimila eticamente também essa irreverência ao seu acabamento estético. Como o título anuncia, o tom jocoso integra o caráter avaliativo do poema, garantindo que o lamento manifesto no verso que liga história e historicização - "Que pena!" - não seja revestido por um possível pranto. O eu que se enuncia não é referido apenas como herdeiro de um legado, mas principalmente como sujeito ideologicamente posicionado e coletivamente identificado. A possibilidade semântico-ideológica da crítica jocosa ao discurso da história integra e altera a memória social e rascunha contornos identitários de projeto.

Assim, afirma-se que a escrita da brasilidade é possível porque a escrita de um Brasil funda um espaço simbólico-discursivo para deflagrar modos de significar o ambiente físico como territorialidade culturalmente costurada: o Brasil. Por isso, as escritas em língua portuguesa participam de modo crucial no delineamento do sentimento de pertença, do senso de propriedade, da percepção de grupo social brasileiro.

\section{CONSIDERAÇÕES FINAIS}

A memória cultural que fundamenta o vernáculo brasileiro encerra o desafio de fazer da língua do outro (e por que não dizer, do Outro) a língua de si. No trajeto dessa empreitada, as alterações ideológicas que o funcionamento do português na territorialidade a ser conhecida como Brasil impinge às relações dialogais e dialógicas constituem peça chave para o estabelecimento do paradoxal português do Brasil. Certamente o foco da política lusófona aqui discutida não recai sobre o sistema de signos 
definidos como língua portuguesa, mas sobre os discursos por ela mediados que permitem estabelecer relações subjetivas e intersubjetivas próprias do Brasil. Dessa perspectiva, a matriz vernacular brasileira constrói-se sobre estratos históricos e simbólicos culturalmente significados e ressignificados a cada investimento de atualização da memória social entretecida a partir do projeto colonizador lusitano. Mais do que registrar nuanças do vernáculo, a escrita primeira e a segunda movimentam o processo de documentação dos laços simbólicos que unem o grupo social identificado como Brasil e sinalizam processos sociodiscursivos que apontam para acabamentos identitários de projeto.

Teórico-metodologicamente, ao articular as dimensões linguística, simbólica e política dos processos de subjetivação e de construção identitária coletiva, este artigo demonstra a produtividade das categorias enunciativo-discursivas de pessoa para a abordagem de fenômenos atualizados na relação língua/cultura. Além disso, ao se afastar do tratamento da intertextualidade entre escrita segunda e primeira, em favor da apreciação das relações interdiscursivas que alimentam a memória cultural determinante do vernáculo brasileiro, este trabalho difere-se dos que buscam recuperar um acabamento estático da identidade nacional, que se traduziria pelo ufanismo, depreciação, estranhamento ou qualquer outro tom avaliativo sobre a historicização do país. O que se propõe é reconhecer nas cicatrizes deixadas pelos múltiplos olhares os movimentos simbólicos que definem a memória social do Brasil, a dinâmica identitária e o senso de vernáculo que os atravessa.

Recebido em junho de 2012 Aprovado em outubro de 2012 E-mail: eumagalhaes@yahoo.com.br

\section{REFERÊNCIAS BIBLIOGRÁFICAS}

Amorim, Marilia. 2009. Memória do objeto - uma transposição bakhtiniana e algumas questões para a educação. Bakhtiniana: Revista de Estudos do Discurso, São Paulo, v. 1, n. 1: 8-22, $1^{\circ}$ sem. 2009.

Bakhtin, Mikhail. 2002. Formas de tempo e de cronotopo no romance (ensaios de poética histórica). In: - Questões de literatura e estética - a teoria do romance. Trad. Aurora Fornoni Bernardini et al. 5. ed. São Paulo: Hucitec: 211-362. 
. Problemas da poética de Dostoievski. 2010. Trad. Paulo Bezerra.

5. ed. Rio de Janeiro: Forense Universitária.

BaKhtin, Mikhail/Volochínov, Valentin. 1999. Marxismo e Filosofia da

Linguagem. Problemas fundamentais do método sociológico na Ciência da Linguagem. Trad. Michel Lahud e Yara Frateschi Vieira. 9. ed. São Paulo: Hucitec.

Bakhurst, David. \& Sypnowich, Christine. (eds.) 1995. The Social Self. Londres: Sage.

Benveniste, Émile. 2005. A natureza dos pronomes. In: _ _ _. Problemas de Lingüística Geral I. Trad. Maria da Glória Novak e Maria Luisa Néri. 5. ed. Campinas: Pontes: 277-283.

Boris, Fausto. 2010. História do Brasil. 13. ed. 2. reimpr. São Paulo: Editora da Universidade de São Paulo.

CAlvet, Louis-Jean. 2007. As políticas linguísticas. Trad. Isabel de Oliveira Duarte, Jonas Tenfen, Marcos Bagno. São Paulo: Parábola Editorial/IPOL.

CÂmara Junior, Joaquim Mattoso. 1975. História e estrutura da língua portuguesa. Rio de Janeiro: Padrão, Prolivro.

Caminha, Pero Vaz de. 1500. Carta a El Rei D. Manuel de 1 de maio. Arquivo Nacional da Torre do Tombo - Portugal, gav. 8, maç. 2, $\mathrm{n}^{\circ}$ 8. Disponível em: http://ttonline.dgarq.gov.pt/dserve.exe?dsqServe $\mathrm{r}=$ calm6\&dsqIni $=$ Dserve. ini\&dsqApp $=$ Archive $\& d s q C m d=$ show. $\mathrm{tcl} \& \mathrm{dsqDb}=$ Catalog $\& \mathrm{dsq} \mathrm{Pos}=0 \& \mathrm{dsqSearch}=\% 28 \mathrm{RefNo}=\% 27 \mathrm{P}$ T-TT-GAV/8/2/8\%27\%29. Acesso em: 03 jan 2012.

Castells, Manuel. 2001. O Poder da Identidade. Trad. Klauss Brandini Gerhardt. A Era da Informação: economia, sociedade e cultura, v. 2, 3. ed. São Paulo: Paz e Terra.

Chamie, Mario. 2002. Caminhos da Carta. Uma leitura antropofágica da carta de Pero Vaz de Caminha. Ribeirão Preto: FUNPEC-RP.

Coutinho, Ismael de Lima. 2005. Gramática histórica. 7. ed. 19. reimpr. Rio de Janeiro: Ao Livro Técnico.

Del Priore, Mary \& Venancio, Renato. 2010. Uma breve história do Brasil. São Paulo: Editora Planeta do Brasil.

Dufour, Dany-Robert. 2005. A arte de reduzir as cabeças: sobre a nova servidão na sociedade ultraliberal. Trad. Sandra Regina Felgueiras. Rio de Janeiro: Companhia de Freud.

Fiorin, José Luiz. 2009. A construção da identidade nacional brasileira. Bakhtiniana - Revista de Estudos do Discurso. São Paulo, v. 1, n. 1: 115-126, $1^{\circ}$ sem. 
Hauy, Amini Boianain. 2008. Séculos XII, XIII e XIV. In: Spina, Segismundo. (org.) História da língua portuguesa. Cotia: Ateliê Editorial: 21-145.

He, Agnes. W. 1995. Co-constructing institutional identities: the case of student counselees. Research on Language and Social Interaction, v. 28, n. 3: 213-231.

Himmelseher, Cecília \& Isensee, Marcela. 2011. Oswald de Andrade no IMS. Blog do IMS, 6 jul. Disponível em: http://blogdoims.uol.com. br/ims/oswald-de-andrade-no-ims/ Acesso em: 10 mar. 2012.

Lopez, Adriana \& Mota, Carlos Guilherme. 2008. História do Brasil: uma interpretação. São Paulo: Editora SENAC São Paulo.

Magalhães, Anderson Salvaterra. 2011. Fundamentos éticos da esfera discursiva da imprensa no Brasil: um jogo de epígrafes e memórias. Trabalhos em Linguística Aplicada (UNICAMP), v. 50, p. 27-43. . 2012. Políticas linguísticas e historicização do Brasil: a escrita na construção vernacular. Gragoatá. Niterói (UFF), n. 32, $1^{\circ}$ sem., no prelo.

Mariani, Bethânia. 2004. Colonização linguística. Línguas, política e religião no Brasil (séculos XVI a XVIII) e nos Estados Unidos da América (século XVIII). Campinas: Pontes.

Noll, Volker. 2010. O Brasil Colônia entre a língua geral e o português. In: Noll, Volker \& Dietrich, Wolf. (ors.) O português e o tupi no Brasil. São Paulo: Contexto: 105-118.

Nunes, José Joaquim. 1989. Compêndio de Gramática Histórica Portuguesa. 9. ed. Lisboa: Lisboa Codex.

Roudinesco, Elisabeth \& Plon, Michel. 1998. Dicionário de psicanálise. Trad. Vera Ribeiro. Rio: Jorge Zahar.

SARuP, Madan. 1996. Identity, Culture and The Postmodern World. Edinburgh: Edingburgh University Press.

SHOtTER, John. 1993. Social accountability and the social construction of 'you'. In: Shotter, John \& Gergen, Kenneth J. (eds.) Texts of Identity. Londres: Sage.

Thiesse, Anne-Marie. 1999. La création des identités nationales. Europe XVIIIe-XXe siècle. Paris: Editions du Seuil.

Voloshinov, Valentin [Mikhail Bakhtin]. 1988. What is language? In: Shukman, Ann (org). Bakhtin school papers. Russian Poetics in Translation. Somerton: Old School House: 93-113. 